Research Article

\section{Dysfunctional breathing in children}

\section{Amanda MP Trompenaars", Aalt PJ Van Roest\# and Anja APH Vaessen-Verberne*}

Department of Paediatrics, Amphia Hospital, Breda, The Netherlands

\#Equal contribution

\section{Abstract}

Objective: Dysfunctional breathing (DB) refers to abnormal patterns of breathing. No gold standard exists for diagnosis. In clinical practice we regularly see children with functional breathing problems. We collected data from this patient group to gain more insight into the characteristics of children with dysfunctional breathing.

Methods: We composed a retrospective, cross-sectional study. The population consisted of children referred to a physiotherapist by a pediatrician due to suspected dysfunctional breathing. Data from 2013-2015 were collected from patient files, selected according to patterns and onset of symptoms, concomitant asthma, Nijmegen questionnaire (NQ) score, maximum exercise capacity and breathing pattern.

Results: A total of 201 patients were included in the study, $66 \%$ of whom were female. The mean age was 13.9 years; $26 \%$ of the children were overweight. The most frequently reported symptoms were breathlessness, chest pain/tightness and dizziness. Fifty-two percent had a $\mathrm{NQ}$ score $\geq 23$, mainly female. Twenty-eight percent of the children scored $<\mathrm{p} 5$ for their age on maximum exercise capacity; this proportion was substantially higher among males. Of the total population, $78 \%$ scored $<$ p50 for their age. Subgroups with a higher body mass index (BMI) showed lower maximum exercise capacity. Children presenting with pulmonary symptoms were primarily misdiagnosed with asthma.

Conclusion: Dysfunctional breathing is a common cause of respiratory complaints. Most children with dysfunctional breathing have a high BMI and are in poor physical condition, which suggests a clinically relevant comorbidity and possible options for therapy. Children are often falsely diagnosed with asthma; better recognition will decrease unnecessary medication use.

\section{More Information}

*Address for Correspondence: Anja APH Vaessen-Verberne, Department of Paediatrics, Amphia Hospital, Molengracht 21, $4818 \mathrm{CK}$ Breda, The Netherlands, Tel: +31 76595 1538; Email: avaessen-verberne@amphia.nl

Submitted: 16 May 2020

Approved: 29 May 2020

Published: 30 May 2020

How to cite this article: Trompenaars AMP Van Roest APJ, Vaessen-Verberne AAPH Dysfunctional breathing in children. J Pulmonol Respir Res. 2020; 4: 001-005

DOI: 10.29328/journal.jprr.1001013

Copyright: (C 2020 Trompenaars AMP, et al This is an open access article distributed under the Creative Commons Attribution License, which permits unrestricted use, distribution, and reproduction in any medium, provided the original work is properly cited

Keywords: Hyperventilation; Breathlessness; Asthma; Maximum exercise capacity; Obesity; Nijmegen questionnaire

Check for updates

OPEN ACCESS

\section{Introduction}

Dysfunctional breathing (DB) describes a group of abnormal breathing patterns. The definition of DB is unclear and no gold standard exists for diagnosis. Symptoms include hyperventilation, breathlessness, chest tightness and chest pain, but also anxiety, light-headedness and fatigue. Besides these symptoms, patients may also exhibit unsteadiness, exercise intolerance, frequent sighing and predominantly non-diaphragmatic respiratory efforts [1,2]. DB may result in either intermittent or chronic complaints. DB often remains undetected or may be falsely diagnosed as asthma, and may therefore be responsible for a serious burden of morbidity and unnecessary medication use.

Boulding, et al. recently proposed a classification of dysfunctional breathing patterns in adults, including hyperventilation syndrome, periodic deep sighing and thoracic dominant breathing [2]. Differentiation can be obtained by using the Nijmegen questionnaire (NQ) or monitoring tidal spirometry, but some overlap in patterns does exist. Coexisting respiratory or cardiac disorders should be ruled out or treated.

In recent years, we have noticed a growing number of patients in our outpatient clinic with functional breathing problems but no underlying cardiac or pulmonary disease. We propose to classify these patients as dysfunctional breathers. In a retrospective study, we collected data on patients referred with suspected dysfunctional breathing in order to gain more insight into the characteristics of children with dysfunctional breathing. In the future we hope for better recognition of these patients, to improve medical management and quality of life.

\section{Methods}

We composed a retrospective, cross-sectional study. The population included all children referred to a specialized pediatric physiotherapist by a pediatrician at our clinic due to suspected dysfunctional breathing in the period 20132015. Our pediatricians had noted each patient's medical 
history and history of complaints, taken standard body measurements and performed a physical examination. If necessary they performed additional investigations to rule out other pathologies.

Following referral, the physiotherapist completed the Nijmegen questionnaire during consultation.

The Nijmegen questionnaire consists of 16 items related to respiratory symptoms, excessive ventilation and central nervous system symptoms. The respondent is asked to rate the occurrence of each symptom on a scale of 0 to 4 [3]. The maximum total score is 64 . A total score of $18-23$ signifies possible symptomatic hyperventilation. A score $\geq 23$ is likely for symptomatic hyperventilation in adults $[3,4]$.

Breathing patterns were evaluated at rest and during exercise, unless dysfunctional breathing was already evident at rest. All children with asthma used bronchodilators before starting the exercise tests. The children underwent standardized exercise tests, namely the Bruce treadmill test (children under the age of 13) or the bicycle test (children aged 13 and older) [5,6]. Reference values for maximum endurance time are available for both tests $[7,8]$, and these were used to determine p-values according to age. When processing the results, we considered the two tests to be equal. Any complaints provoked during the exercise test were noted.

The following data were extracted from digital patient files: demographics, history of complaints, time since onset of symptoms, pre-existing diagnosis of asthma, asthma medication, NQ score, maximum exercise capacity related to age, and any complaints and/or dysfunctional breathing provoked during the exercise test. With regard to body mass index (BMI), standard deviation scores (SDS) were determined according to Dutch reference values [9]. We determined each patient's main complaint (symptom) subjectively in order to classify them as presenting with 'pulmonary symptoms', 'cardiac symptoms', or 'other symptoms'.

All outcomes were performed using SPSS Statistics 24.0 (IBM, SPSS Inc., Armonk, NY). Besides basic descriptive tests, we also used t-tests to compare means, chi-squared tests to compare proportions and correlation tests (Pearson's) to determine correlations. The one-way ANOVA test and Jonckheere-Terpstra test were used to determine correlations between various parameters.

\section{Results}

A total of 201 patients were included in the study, 66\% of whom were female (Table 1). BMI SDS were distributed normally (median 0.64, interquartile range 1.74) in our population. The mean BMI SDS of the patients in the study population was higher than the BMI of the overall population in the same age category: $26 \%$ of the children in our population were overweight (BMI SDS 1-2) and 13\% were obese (BMI SDS > 2). The symptoms recorded during consultation are listed in table 2 . The most frequently reported symptom was breathlessness, followed by chest pain/tightness and dizziness. Sixty percent of the children had been experiencing symptoms for more than 6 months.

\section{Nijmegen questionnaire}

NQ scores were available for 175 patients (Table 3). The mean NQ score was $22.8 \pm 9.7$. More than half of the patients had NQ scores $\geq 23$, indicating dysfunctional breathing. Seventeen percent had NQ scores of 18-23, indicating possible dysfunctional breathing. Mean NQ sores in females were significantly higher than in males $(p=0.001)$. Mean NQ

\begin{tabular}{|c|c|c|}
\hline \multirow{2}{*}{ Sex } & Female & $132(65.7)$ \\
\hline & Male & 69 (34.3) \\
\hline \multicolumn{2}{|c|}{ Age (years) } & $13.9 \pm 2.3$ \\
\hline \multirow{3}{*}{ BMI SDS } & Mean value & $0.66 \pm 1.17$ \\
\hline & BMI SDS 1-2 & $51(26.2)$ \\
\hline & BMI SDS > 2 & $25(12.8)$ \\
\hline \multirow{3}{*}{$\begin{array}{l}\text { Predominant } \\
\text { symptoms }\end{array}$} & Pulmonary & $107(53.2)$ \\
\hline & Cardiac & $52(25.9)$ \\
\hline & Other & $42(20.9)$ \\
\hline \multirow{5}{*}{$\begin{array}{l}\text { Duration of } \\
\text { symptoms }\end{array}$} & $>3$ months & $35(17.9)$ \\
\hline & 4-6 months & $43(22.1)$ \\
\hline & 6-12 months & $37(19.0)$ \\
\hline & $1-2$ years & $33(16.9)$ \\
\hline & $>2$ years & $47(24.1)$ \\
\hline \multicolumn{2}{|c|}{ Asthma diagnosis } & $53(26.4)$ \\
\hline \multicolumn{3}{|c|}{$\begin{array}{l}\text { Data are presented as } n(\%) \text {, mean } \pm \text { SD } \\
\text { BMI: Body Mass Index; SDS: Standard Deviation Score }\end{array}$} \\
\hline
\end{tabular}

\begin{tabular}{|c|c|}
\hline \multicolumn{2}{|c|}{ Table 2: Symptoms reported by the children during consultation. } \\
\hline Reported symptoms (\% children) \\
\hline Breathlessness & 76.6 \\
\hline Chest pain/tightness & 51.2 \\
\hline Dizziness & 49.8 \\
\hline Headache & 33.8 \\
\hline Palpitations & 25.4 \\
\hline Tingling & 23.4 \\
\hline Tiredness & 22.9 \\
\hline Hyperventilation & 16.4 \\
\hline Coughing & 16.4 \\
\hline Tight throat & 15.9 \\
\hline Reduced exercise tolerance & 10.0 \\
\hline Anxiety & 9.0 \\
\hline Sucking & 0 \\
\hline
\end{tabular}

\section{Table 3: NQ scores.}

\begin{tabular}{|c|c|c|c|}
\hline & All children & Female & Male \\
\hline Total & 173 & 117 & 56 \\
\hline NQ score & $22.8 \pm 9.7$ & $24.4 \pm 9.7$ & $19.4 \pm 8.9$ \\
\hline NQ score $\geq 23$ & $90(52.0)$ & $70(59.8)$ & $20(35.7)$ \\
\hline NQ score $18-23$ & $30(17.3)$ & $17(14.5)$ & $13(23.2)$ \\
\hline NQ score $<18$ & $53(30.6)$ & $30(25.6)$ & $23(41.1)$ \\
\hline
\end{tabular}

Data are presented as $n(\%)$, mean $\pm S D$

NQ: Nijmegen Questionnaire 
scores did not differ significantly between children with a prior history of asthma and those without $(23.9 \pm 9.4$ vs. 22.3 \pm 9.8 respectively; $p=0.35$ ). BMI SDS and NQ score were not significantly correlated ( $p=0.08$ ). No significant difference was found in mean NQ score between children who presented with 'pulmonary', 'cardiac' or 'other' symptoms ( $p=0.32)$.

\section{Maximum exercise test}

A total of 191 patients underwent an exercise test (Figure 1). Ten children exhibited dysfunctional breathing at rest and were therefore not required to perform an exercise test. Fifty-four children (28\%) demonstrated a maximum exercise capacity < p5 for their age, and 149 children (78\%) had a score $<$ p50 for their age. Males showed significantly lower levels of exercise capacity than did females ( $p=0.005)$. Maximum exercise capacity was negatively correlated with BMI SDS $(p<0.001)$, meaning that children with higher BMI SDS demonstrated lower maximum exercise capacity.

In 154 children (80.6\%), the exercise test provoked dysfunctional breathing as well as certain other symptoms specific to each child.

\section{Asthma}

Fifty-three children (26\%) had a previous history of asthma, diagnosed prior to the onset of dysfunctional breathing symptoms. Most of them experienced respiratory symptoms without positive effect of their asthma medication. Dysfunctional breathing was regarded as a comorbidity.

Thirty-two children (16\%) were using asthma medication before referral, but the pediatric lung specialist excluded the diagnosis of asthma. Evaluation by the specialized physiotherapist showed dysfunctional breathing. Half of this group were even using inhaled corticosteroids or a combination of inhaled corticosteroid and long-acting beta-2-agonists before referral. Misdiagnosis with asthma had occurred mainly in children presenting with pulmonary symptoms, in particular.

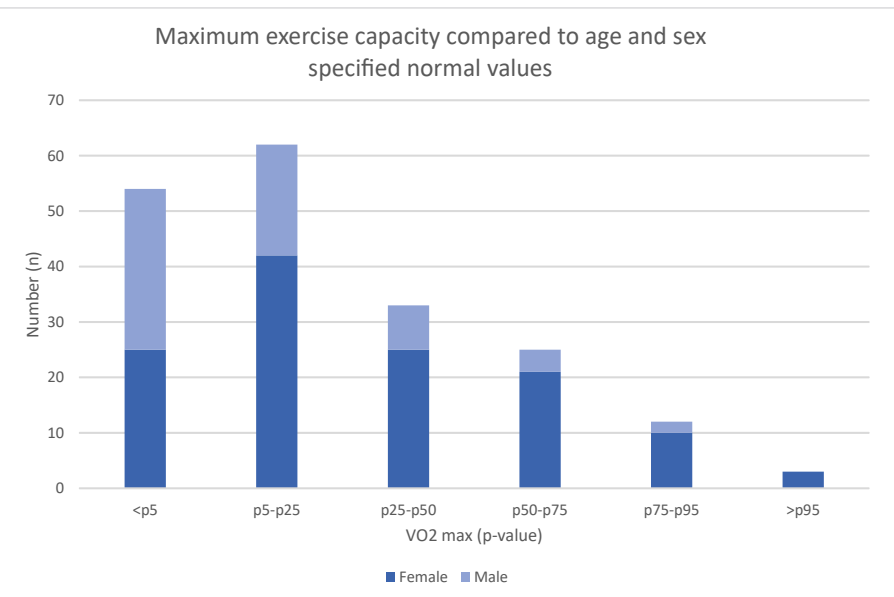

Figure 1: Maximum exercise capacity compared to normal values per age and sex.

\section{Discussion}

In this study, we describe a group of 201 children who presented at our clinic with symptoms suggestive of dysfunctional breathing. We collected data to gain more insight into the characteristics of children with dysfunctional breathing. The most common presenting symptom was breathlessness, followed by chest pain/tightness and dizziness. A large proportion of the children were overweight or obese. More than half of the patients had high NQ scores, suggesting dysfunctional breathing. During maximum exercise tests, we were able to provoke abnormal breathing patterns in the majority of the children. The exercise tests also revealed poor physical condition. Some children with dysfunctional breathing had been misdiagnosed with asthma.

There is currently no gold standard for diagnosing dysfunctional breathing. A common test used for diagnosis is the Nijmegen questionnaire (NQ) [3], but this questionnaire has not been validated for use in children. In our study, NQ scores suggested dysfunctional breathing (score $\geq 18$ ) in $69 \%$ of the children. Mean NQ sores in females were higher than in males, although we could not find a possible explanation for this. Previous studies in adults have indicated an overdiagnosis of dysfunctional breathing among asthma patients when based on the NQ compared to results from progressive exercising tests $[10,11]$. In our study, NQ values did not differ between children with asthma and those without, so it is unlikely that overestimation of NQ values occurred. While the literature has proposed more objective measurements of breathing patterns during rest and exercise (such as manual assessment of respiratory motion [12] and, more recently, optoelectronic plethysmography [13]), these measurements are not widely used in clinical practice, and especially not in children. In this study, breathing patterns at rest and during maximum exercise tests were therefore assessed by trained physiotherapists. We found that exercise testing provoked abnormal breathing patterns and symptoms specific to each child (as mentioned in their histories) in $80 \%$ of the children. We conclude that exercise tests provoking symptoms and enabling the evaluation of abnormal breathing patterns is a better means of diagnosing dysfunctional breathing in children than is the NQ.

Maximum exercise testing also revealed that a substantial number of the children were in strikingly poor physical condition. We found no direct relationship between dysfunctional breathing and poor physical condition in the literature, however. Poor physical condition could perhaps be explained by the high incidence of overweight and obesity in our population. BMI SDS was found to be an independent risk factor for functional exercise capacity as measured by the six-minute walk test in children, irrespective of lung function parameters [14]. However, the large proportion of children who were in poor physical condition in the overall group might suggest a direct relationship between dysfunctional breathing 
and exercise capacity. It remains unclear whether it is low exercise capacity that leads to dysfunctional breathing or dysfunctional breathing that leads to poor physical condition through exercise avoidance. This finding could indicate possible additional therapeutic targets for children with DB.

Regarding the high incidence of overweight children in our population, we were unable to find any existing data on the relationship between obesity and dysfunctional breathing. In a large survey among adults, however, Sin et al. reported a relationship between BMI and the risk of self-reported asthma, bronchodilator use and dyspnea upon exertion, where the highest BMI quintile (BMI $>31.0 \mathrm{~kg} / \mathrm{m}^{2}$ ) demonstrated the lowest risk of significant airflow obstruction [15]. The high BMI group also reported lower levels of physical activity in the previous month. The authors suggest that asthma may be overdiagnosed in obese adults. Our study also revealed misdiagnoses of asthma, though this was not related to BMI. The Sin et al. survey did not include evaluation of breathing patterns, so no data are available in that respect.

Dysfunctional breathing is more prevalent in patients with asthma than in non-asthmatics, both in adults [4] and in children [16]. De Groot, et al. reported a dysfunctional breathing incidence of $5.3 \%$ in children with severe or difficult-to-control asthma, based solely on NQ scores [17]. In that study population, dysfunctional breathing was found to be related to poorer asthma control. Asthmatic children were also represented in our cohort: those were children whose pediatricians suspected that dysfunctional breathing was contributing to their pulmonary symptoms. Of this subgroup (consisting of 53 children), 25 children had NQ scores $>23$; however, all children demonstrated abnormal breathing patterns during exercise tests. Although we cannot rule out the simultaneous occurrence of asthma symptoms, no wheezing/ coughing was reported during the exercise tests and all previously diagnosed asthmatic children used bronchodilators before the exercise tests to minimalize negative influence of asthmatic symptoms. Our results confirm the presence of comorbidity for dysfunctional breathing in children with (poorer controlled) asthma. Asthmatic children with poorer asthma control need to be tested for dysfunctional breathing as well, since additional treatment for DB can improve symptoms.

A striking finding is that 32 children in our cohort had been previously misdiagnosed with asthma. Clinical evaluation of these children did not confirm the asthma diagnosis, but revealed respiratory complaints caused by dysfunctional breathing. Symptoms resolved after physiotherapy training for breathing problems, mostly in combination with physical training activities. Asthma medication was discontinued in this group.

\section{Conclusion}

Our retrospective study found the Nijmegen questionnaire to be an insufficiently sensitive test for diagnosing dysfunctional breathing in children. More accurate diagnoses may be obtained by having trained physiotherapists evaluate breathing patterns during maximum exercise tests that provoke abnormal breathing. The majority of the children included in our study also showed limited exercise capacity and were overweight, which suggests a clinically relevant comorbidity and revealing additional therapeutic targets. Children presenting with pulmonary symptoms are at particular risk of being misdiagnosed with asthma. Maximum exercise tests may be a helpful examination to improve the context that doctors give children unnecessary asthma medication.

\section{Acknowledgments}

We would like to thank specialized pediatric physiotherapists Pascalle Andreoli and Sandra Oude Sogtoen for their help with completing the Nijmegen questionnaires and for carrying out the maximum exercise tests in all of the children.

\section{Declaration of interest statement}

The authors report no conflicts of interest. The authors alone are responsible for the content and writing of the paper.

\section{References}

1. Barker N, Everard ML. Getting to grips with 'dysfunctional breathing'. Paediatr Respir Rev. 2015; 16: 53-61.

PubMed: https://www.ncbi.nlm.nih.gov/pubmed/25499573

2. Boulding R, Stacey R, Niven R, Fowler SJ. Dysfunctional breathing: a review of the literature and proposal for classification. Eur Respir Rev. 2016; 25: 287-294.

PubMed: https://www.ncbi.nlm.nih.gov/pubmed/27581828

3. van Dixhoorn J, Duivenvoorden HJ. Efficacy of Nijmegen Questionnaire in recognition of the hyperventilation syndrome. J Psychosom Res. 1985; 29: 199-206.

PubMed: https://www.ncbi.nlm.nih.gov/pubmed/4009520

4. Thomas M, McKinley RK, Freeman E, Foy C, Price D. The prevalence of dysfunctional breathing in adults in the community with and without asthma. Prim Care Respir J. 2005 14: 78-82.

PubMed: https://www.ncbi.nlm.nih.gov/pubmed/16701702

5. Lear SA, Brozic A, Myers JN, Ignaszewski A. Exercise stress testing An overview of current guidelines. Sports Med. 1999; 27: 285-312. PubMed: https://www.ncbi.nlm.nih.gov/pubmed/10368877

6. Stuart RJ, Jr., Ellestad MH. National survey of exercise stress testing facilities. Chest. 1980; 77: 94-97.

PubMed: https://www.ncbi.nlm.nih.gov/pubmed/7351157

7. van der Cammen-van Zijp MH, van den Berg-Emons RJ, Willemsen SP, Stam HJ, Tibboel D, H IJ. Exercise capacity in Dutch children: new reference values for the Bruce treadmill protocol. Scand J Med Sci Sports. 2010; 20: e130-136.

PubMed: https://www.ncbi.nlm.nih.gov/pubmed/19422656

8. Gulmans VA, de Meer K, Binkhorst RA, Helders PJ, Saris WH Reference values for maximum work capacity in relation to body composition in healthy Dutch children. Eur Respir J. 1997; 10: 94-97. PubMed: https://www.ncbi.nlm.nih.gov/pubmed/9032499

9. TNO Groeicalculator voor professionals: TNO (toegepastnatuurwetenschappelijk onderzoek); 2010. https://groeiweb.pgdata.nl/calculator.asp 
10. Stanton $A E$, Vaughn $P$, Carter $R$, Bucknall $C E$. An observationa investigation of dysfunctional breathing and breathing control therapy in a problem asthma clinic. J Asthma. 2008; 45: 758-765.

PubMed: https://www.ncbi.nlm.nih.gov/pubmed/18972291

11. Agache I, Ciobanu C, Paul G, Rogozea L. Dysfunctional breathing phenotype in adults with asthma - incidence and risk factors. Clin Transl Allergy. 2012; 2: 18.

PubMed: https://www.ncbi.nlm.nih.gov/pubmed/22992302

12. Courtney R, van Dixhoorn J, Cohen M. Evaluation of breathing pattern comparison of a Manual Assessment of Respiratory Motion (MARM) and respiratory induction plethysmography. Appl Psychophysiol Biofeedback. 2008; 33: 91-100.

PubMed: https://www.ncbi.nlm.nih.gov/pubmed/18320303

13. Parreira VF, Vieira DS, Myrrha MA, Pessoa IM, Lage SM, Britto RR Optoelectronic plethysmography: a review of the literature. Rev Bras Fisioter. 2012; 16: 439-453.

PubMed: https://www.ncbi.nlm.nih.gov/pubmed/23184278
14. Ozgen IT, Cakir E, Torun E, Gules A, Hepokur MN, Cesur Y. Relationship Between Functional Exercise Capacity and Lung Functions in Obese Chidren. J Clin Res Pediatr Endocrinol. 2015; 7: 217-221.

PubMed: https://www.ncbi.nlm.nih.gov/pmc/articles/PMC4677557/

15. Sin DD, Jones RL, Man SF. Obesity is a risk factor for dyspnea but not for airflow obstruction. Arch Intern Med. 2002;162: 1477-1481. PubMed: https://www.ncbi.nlm.nih.gov/pubmed/12090884

16. Gridina I, Bidat E, Chevallier B, Stheneur C. Prevalence of chronic hyperventilation syndrome in children and teenagers. Arch Pediatr. 2013; 20: 265-268.

PubMed: https://www.ncbi.nlm.nih.gov/pubmed/23375424

17. de Groot EP, Duiverman EJ, Brand PL. Dysfunctional breathing in children with asthma: a rare but relevant comorbidity. Eur Respir J. 2013; 41: 1068-1073.

PubMed: https://www.ncbi.nlm.nih.gov/pubmed/23018913 